\title{
Comparação entre avaliações de linguagem na infância e sua relação com risco psíquico
}

\author{
Comparison between language \\ assessments in childhood and its \\ relationship to psychic risk
}

\section{Comparación entre las evaluaciones lingüísticas en la niñez y su relación con el riesgo psíquico}

\author{
Camila Gomes Nazario* \\ Inae Costa Rechia* \\ Isabela de Moraes Fattore* \\ Sabrina Felin Nunes* \\ Ana Paula Ramos de Souza*
}

\section{Resumo}

Objetivo: Comparar os resultados das avaliações de linguagem obtidas por protocolos centrados nas habilidades das crianças com os resultados de uma análise enunciativa em casos de atraso de linguagem, relacionando-os ao psiquismo. Método: Estudo de caso longitudinal, qualitativo, com três crianças de 24 meses. Elas foram avaliadas em suas habilidades linguísticas por meio dos protocolos DENVER II e BAYLEY III. A avaliação enunciativa foi realizada por meio da análise dos vídeos das interações entre as mães e os bebês a partir dos quais foram identificados os mecanismos e estratégias enunciativas. O risco psíquico foi avaliado por meio dos Indicadores Clínicos de Referência ao Desenvolvimento Infantil (IRDI) e Sinais PREAUT e comparado aos resultados do MCHAT. Resultados: As avaliações de linguagem demonstraram que o teste Bayley III é mais sensível ao atraso no domínio gramatical do que o Denver II. As análises enunciativas demonstraram a limitação nos mecanismos enunciativos no

* Universidade Federal de Santa Maria - UFSM, Santa Maria, RS, Brasil

Contribuição dos autores:

CGN - Coleta dos dados e redação do artigo; ICR e SFN - análise dos dados e coorientação; IMF - redação do artigo e coorientação; APRS - revisão do artigo e orientação

E-mail para correspondência: Camila Gomes Nazario bililagn@gmail.com Recebido: $22 / 05 / 2018$

Aprovado: $27 / 11 / 2018$ 
caso de risco psíquico mais grave, mas também as potencialidades linguísticas das crianças. Conclusão: A comparação permitiu identificar a diferença entre testes padronizados e a avaliação enunciativa, pois a limitação em mecanismos enunciativos e em alguns itens relacionados ao endereçamento da fala ao outro no teste Bayley III permitiu identificar as limitações de linguagem relacionadas com as alterações na intersubjetividade.

Palavras-chave: Linguagem Infantil; Avaliação; Sintomas psíquicos.

\section{Abstract}

Objective: To compare the results of language assessments obtained by protocols centered on children's abilities with the results of an enunciative analysis in cases of language delay, relating them to the psychism. Method: A qualitative, longitudinal case study with three 24-month-old children. They were evaluated in their language skills through the DENVER II and BAYLEY III protocols. The enunciative evaluation was carried out by means of the analysis of the videos of the interactions between the mothers and the babies from which the enunciative mechanisms and strategies were identified. The psychological risk was evaluated through the Clinical Indicators for Infant Development (IRDI) and PREAUT Signs, and it was compared with M-CHAT. Results: The language evaluations demonstrated that the Bayley III test is more sensitive to delay in the grammatical domain than the Denver II. The enunciative analyzes demonstrated the limitation in the enunciative mechanisms in the case of more severe psychic risk, but also the linguistic potential of the children. Conclusion: The comparison made it possible to identify the difference between standardized tests and the enunciative evaluation, since the limitation in enunciative mechanisms and some items related to speech addressing to the other in the Bayley III test allowed to identify the language limitations related to the changes in intersubjectivity.

Keywords: Infant language; Evaluation; Psychic symptoms.

\section{Resumen}

Objetivo: Comparar los resultados de lãs evaluaciones de lenguaje obtenidas porprotocolos centrados en las habilidades de los niños com los resultados de um análisis enunciativo em casos de retraso Del lenguaje, relacionando los al psiquismo. Método: Estudio de casos longitudinal, cualitativo, contresniños de 24 meses. Se evaluaron en sus habilidades lingüísticas a través de losprotocolos DENVER II y BAYLEY III. La evaluación enunciativa fue realizada por médio del análisis de los videos de lãs interacciones entre las madres y los bebés a partir de loscuales se identificaron lós mecanismos y estratégias enunciativas. El psiquismo fue evaluado por medio de los Indicadores Clínicos de Referencia al DesarrolloInfantil (IRDI)y Señales PREAUT, y se ha comparado com M-CHAT.Resultados: Las evaluaciones de lenguaje demostraron que la prueba Bayley III ES más sensible al retraso em el domínio gramatical que el Denver II. Los análisis enunciativos demostraron La limitación en los mecanismos enunciativos enel caso de riesgopsíquicomás grave, perotambién las potencialidades lingüísticas de los niños. Conclusión: La comparación permitió identificarla diferencia entre pruebas estandarizadas y La evaluación enunciativa, pues La limitación em mecanismos enunciativos y em algunos ítems relacionados al direccionamientodelhabla al outro em laprueba Bayley III permitieron identificar lãs limitaciones de lenguaje relacionadas con los câmbios em La intersubjetividad.

Palabras claves: Lenguaje Infantil; Evaluación; Síntomas psíquicos. 


\section{Introdução}

Na Fonoaudiologia é usual que se utilizem testes padronizados na avaliação de linguagem das crianças que chegam com atraso na aquisição da linguagem ou suspeita de distúrbio de linguagem. Os testes permitem estabelecer uma comparação das habilidades de compreensão e produção da criança em relação a uma média prevista na população falante de determinada língua ou crianças de qualquer país. Esse é o caso de instrumentos como o Teste de Triagem de Desenvolvimento de Denver II (DENVER II) $)^{1,2}$, que avalia os domínios da linguagem, motricidade fina e ampla, e pessoal-social. Este teste tem sido utilizado na realidade brasileira ${ }^{1,2}$ bem como a escala Bayley Scales of Infant and Toddler Development - Third Edition (Bayley III) ${ }^{3}$, padronizada com referências normativas para crianças de um a 42 meses de idade. Este se divide em cinco subescalas, entre as quais estão a de linguagem e a de cognição. A escala de linguagem avalia habilidades linguísticas básicas para a comunicação da criança, e a escala cognitiva aborda como a criança pensa, reage e aprende sobre o mundo ao seu redor. Diversos estudos afirmam a escala Bayley III como referência para avaliação de bebês ${ }^{4-7}$.

Esses testes, em geral, apresentam uma visão que enfoca mais as habilidades infantis por se basearem em visões clássicas de aquisição da linguagem como a psicolinguística, sobretudo de inspiração inatista ${ }^{8}$, sem levar em consideração princípios como a intersubjetividade que revelam a importância do adulto na sustentação enunciativa da criança durante o processo de aquisição, conforme é possível observar nos itens de linguagem do Bayley III aos 24 meses quando comparados aos do Denver II dispostos no Quadro 1.

De modo distinto, um roteiro de avaliação com inspiração enunciativo-discursiva permite que se aborde o funcionamento da linguagem infantil na relação com o adulto que exerce as funções parentais. Isso possibilita a formulação de uma hipótese de funcionamento de linguagem em que se pode escutar o sintoma de linguagem na clínica com a criança pequena ${ }^{9,10}$ e planejar uma intervenção que inclui os familiares e não apenas a criança. Permite que se possa compreender como o funcionamento de linguagem se articula ao psiquismo ${ }^{9}$, já que a linguagem é tão estruturante quanto os aspectos biológico, cognitivo e psíquico ${ }^{9,10}$.
Nessa perspectiva enunciativa, o princípio da intersubjetividade parece importantíssimo na compreensão do funcionamento de linguagem infantil em crianças com atraso de linguagem e com risco psíquico, já que suas interações linguísticas se modificam a depender do interlocutor, quando são analisadas em situação de diálogo, o que pode permitir melhor compreensão da direção da intervenção. A perspectiva enunciativa possibilita a inclusão do sujeito na cena linguística ${ }^{10,11}$.

Em termos comparativos é possível afirmar que enquanto a análise psicolinguística clássica enfoca aspectos como vocabulário, sintaxe, morfologia, fonologia e pragmática, com foco na compreensão e produção de fala infantil, a análise enunciativo-discursiva tem como foco como se dá o uso do conhecimento gramatical no diálogo como o alocutário, e busca observar que espaço de fala ou posição discursiva a criança pode ocupar no diálogo com o adulto e outras crianças. Cabe ao fonoaudiólogo questionar que elementos cada tipo de avaliação pode trazer para sua intervenção. Acredita-se que isso depende não só da concepção de linguagem que possui, mas também da concepção de sujeito assumida pelo profissional. Quando a concepção de linguagem inclui o sujeito, torna-se necessária a observação de como o sujeito opera na linguagem e não apenas o mapeamento dos subdomínios gramaticais ${ }^{10,11}$. Neste sentido, a intervenção irá contar com essa informação e não será apenas com o bebê ou criança pequena, mas incluirá seus cuidadores primordiais ${ }^{11}$.

Considerando tais aspectos, este estudo objetiva comparar as avaliações de linguagem obtidas por protocolos centrados nas habilidades dos bebês com uma análise enunciativa da linguagem na comparação de atrasos de linguagem em bebês de 24 meses, com e sem histórico de risco psíquico.

\section{Material e Método}

Trata-se de um estudo de caso longitudinal, de caráter qualitativo em que os sujeitos foram submetidos a avaliações de linguagem, de risco psíquico e avaliação auditiva nos dois primeiros anos de vida.

A amostra de conveniência foi composta por três casos escolhidos em uma amostra maior de crianças acompanhadas no projeto de pesquisa aprovado no Comitê de Ética em Pesquisa da Universidade sob número de CAEE 28586914.0.0000.5346. Os critérios de escolha dos 
sujeitos para este estudo de casos foram: presença/ ausência das variáveis como risco psíquico, de tipo autista e não autista, da prematuridade, e um caso de atraso na aquisição da linguagem, sem evidência de risco psíquico. Deste modo a amostra ficou composta do seguinte modo: uma criança prematura com atraso de linguagem sem risco psíquico (P) e duas crianças nascidas a termo com atraso de linguagem e com risco psíquico (A e R). A criança A. representa o risco psíquico de tipo não autista e a criança R. o risco psíquico de tipo autista.

A proposta deste trabalho foi a de fazer uma leitura do histórico de cada criança a partir dos testes coletados em uma unidade básica de saúde, a partir da observação e filmagem das interações mãe-bebê para análise da linguagem, roteiros de avaliação de risco psíquico: IRDI ${ }^{12}$ (ver quadro 1) e Sinais PREAUT ${ }^{13}$ (ver quadro 2). Os resultados desses dois instrumentos foram comparados ao M-CHAT-Modified Checklist for Autism in Toddlers ${ }^{14}$ ), instrumento tradicional de risco para autismo na perspectiva desenvolvimentista. Também foram confrontados com aplicação de avaliações de desenvolvimento da linguagem nos bebês (DENVER $\mathrm{II}^{1}$ e BAYLEY III $^{3}$ ). Além dessas avaliações, foram analisados os resultados da avaliação auditiva por meio do PEAC (Potencial Evocado Auditivo Cortical) da criança prematura $1,6,12$ e 24 meses.

O IRDI estabelece um conjunto de itens observáveis nos primeiros 18 meses de vida da criança, baseados na teoria psicanalítica, cuja ausência pode indicar uma perturbação do curso evolutivo da criança. Os 31 itens do protocolo foram analisados em suas quatro faixas etárias organizadas a partir dos primeiros quatro meses (fase I), entre quatro e oito (fase II), entre oito e doze (fase III) e entre doze e dezoito meses (fase IV). Eles são baseados em quatro eixos teóricos: estabelecimento de demanda, suposição de sujeito, alternância, presença e ausência e função paterna ${ }^{12}$, como se pode ver no Quadro 1.

Quadro 1. Indicadores de risco ao desenvolvimento infantil

\begin{tabular}{|c|c|}
\hline $\begin{array}{l}\text { Faixa } \\
\text { Etária }\end{array}$ & IRDI \\
\hline $\begin{array}{l}1 \mathrm{~A} \\
3 \text { meses } \\
29 \mathrm{~d}\end{array}$ & $\begin{array}{l}\text { 1- Quando a criança chora ou grita, a mãe sabe o que ela quer. } \\
\text { 2- A mãe fala com a criança num estilo particularmente dirigido a ela (mamanhês). } \\
\text { 3- A criança reage ao mamanhês. } \\
\text { 4- A mãe propõe algo à criança e aguarda a sua reação. } \\
\text { 5- Há trocas de olhares entre a criança e a mãe. }\end{array}$ \\
\hline $\begin{array}{l}4 A \\
7 \text { meses } \\
29 d\end{array}$ & $\begin{array}{l}\text { 6- A criança começa a diferenciar o dia da noite. } \\
\text { 7- A criança utiliza sinais diferentes para expressar suas diferentes necessidades. } \\
\text { 8- A criança solicita a mãe e faz um intervalo para aguardar sua resposta. } \\
\text { 9- A mãe fala com a criança dirigindo-Ihe pequenas frases. } \\
\text { 10- A criança reage (sorri, vocaliza) quando a mãe ou outra pessoa está sedirigindo a ela. } \\
\text { 11- A criança procura ativamente o olhar da mãe. } \\
\text { 12- A mãe dá suporte às iniciativas da criança sem poupar-lhe o esforço. } \\
\text { 13- A criança pede a ajuda de outra pessoa sem ficar passiva. }\end{array}$ \\
\hline $\begin{array}{l}8 \mathrm{~A} \\
11 \text { meses } \\
29 \mathrm{~d}\end{array}$ & $\begin{array}{l}\text { 14- A mãe percebe que alguns pedidos da criança podem ser uma forma de chamar a sua atenção. } \\
\text { 15- Durante os cuidados corporais, a criança busca ativamente jogos e brincadeiras amorosas com a } \\
\text { mãe. } \\
\text { 16- A criança demonstra gostar ou não de alguma coisa. } \\
\text { 17- Mãe e criança compartilham uma linguagem particular. } \\
\text { 18- A criança estranha pessoas desconhecidas para ela. } \\
\text { 19- A criança possui objetos prediletos. } \\
\text { 20- A criança faz gracinhas. } \\
\text { 21- A criança busca o olhar de aprovação do adulto. } \\
\text { 22- A criança aceita alimentação semi-sólida, sólida e variada. }\end{array}$ \\
\hline $\begin{array}{l}12 \text { a } 18 \\
\text { meses }\end{array}$ & $\begin{array}{l}\text { 23- A mãe alterna momentos de dedicação à criança com outros interesses. } \\
\text { 24- A criança suporta bem as breves ausências da mãe e reage às ausências prolongadas. } \\
\text { 25- A mãe oferece brinquedos como alternativas para o interesse da criança pelo corpo materno. } \\
\text { 26- A mãe já não se sente mais obrigada a satisfazer tudo que a criança pede. } \\
\text { 27- A criança olha com curiosidade para o que interessa à mãe. } \\
\text { 28- A criança gosta de brincar com objetos usados pela mãe e pelo pai. } \\
\text { 29- A mãe começa a pedir à criança que nomeie o que deseja, não se contentando apenas com gestos. } \\
\text { 30- Os pais colocam pequenas regras de comportamento para a criança. } \\
\text { 31- A criança diferencia objetos maternos, paternos e próprios. }\end{array}$ \\
\hline
\end{tabular}

Fonte: Kupfer, (2008) 
Já a pesquisa dos Sinais PREAUT tem como objetivo mais específico a detecção de risco de evolução para o autismo. Esse questionário analisa as reações do bebê ao manhês, feito pela mãe ou pelo substituto dela, bem como se há ou não a tomada de iniciativa de chamar atenção do adulto após cessar o manhês ${ }^{13}$. Como demonstrado na tabela, esse protocolo foi analisado no quarto e no nono mês da criança, como está disposto no Quadro 2.

Quadro 2. Questionário sinais Preaut

\begin{tabular}{|c|c|c|}
\hline QUESTÃO & RESPOSTA & VALOR \\
\hline \multicolumn{3}{|l|}{ 1) O bebê procura olhar para você ? } \\
\hline \multirow{2}{*}{ a) Espontaneamente } & Sim & 4 \\
\hline & Não & 0 \\
\hline \multirow{2}{*}{ b) Quando você fala com ele (proto-conversação) } & Sim & 1 \\
\hline & Não & 0 \\
\hline \multicolumn{3}{|l|}{ 2) O bebê procura se fazer olhar por sua mãe (ou pelo substituto dela)? } \\
\hline \multirow{2}{*}{$\begin{array}{l}\text { a) Na ausência de qualquer solicitação da mãe, } \\
\text { vocalizando, gesticulando ao mesmo tempo em que a olha } \\
\text { intensamente. }\end{array}$} & Sim & 8 \\
\hline & Não & 0 \\
\hline \multirow{2}{*}{ b) Quando ela fala com ele (proto-conversação) } & $\operatorname{Sim}$ & 2 \\
\hline & Não & 0 \\
\hline \multicolumn{2}{|l|}{ ESCORE TOTAL } & 15 \\
\hline \multicolumn{3}{|l|}{ Se inferior a 5 aplicar questões 3 e 4} \\
\hline \multicolumn{3}{|l|}{ 3) Sem qualquer estimulação de sua mãe (ou de seu substituto) } \\
\hline \multirow{2}{*}{ a) Ele olha para sua mãe (ou para seu substituto) } & Sim & 1 \\
\hline & Não & 0 \\
\hline \multirow{2}{*}{ b) Ele sorri para sua mãe (ou para seu substituto) } & Sim & 2 \\
\hline & Não & 0 \\
\hline \multirow{2}{*}{$\begin{array}{l}\text { c) O bebê procura suscitar uma troca prazerosa com sua mãe (ou } \\
\text { seu substituto), por exemplo, se oferecendo ou estendendo em sua } \\
\text { direção os dedos do seu pé ou da sua mão? }\end{array}$} & Sim & 4 \\
\hline & Não & 0 \\
\hline \multicolumn{3}{|l|}{ 4) Depois de ser estimulado por sua mãe (ou pelo seu substituto) } \\
\hline \multirow{2}{*}{ a) Ele olha para sua mãe (ou para seu substituto) } & Sim & 1 \\
\hline & Não & 0 \\
\hline \multirow{2}{*}{ b) Sorri para sua mãe (ou para seu substituto) } & Sim & 2 \\
\hline & Não & 0 \\
\hline \multirow{2}{*}{$\begin{array}{l}\text { c) O bebê procura suscitar a troca jubilatória com sua mãe (ou com } \\
\text { seu substituto), por exemplo, se oferecendo ou estendendo em sua } \\
\text { direção os dedos do seu pé ou da sua mão? }\end{array}$} & Sim & 4 \\
\hline & Não & 0 \\
\hline \multicolumn{2}{|l|}{ ESCORE TOTAL } & 15 \\
\hline
\end{tabular}

Fonte: Crespin, (2015)

O M-CHAT foi desenvolvido com a finalidade de identificar crianças com risco de autismo a partir dos 18 meses de vida, sendo que nesta pesquisa foi analisado aos 24 meses. Apresenta 23 questões que se dividem em questões referentes a relacionamento social e atenção conjunta, com objetivo de avaliar a emergência da intersubjetividade e, em sua ausência, o risco de autismo ${ }^{14}$. Foi utilizado nesta pesquisa pela valorização que possui na literatura internacional como um teste sensível e específico para triagem de autismo como se pode observar no Quadro 3, embora sua perspectiva difira da perspectiva de psiquismo adotada nesta pesquisa. 
Quadro 3. M-Chat-Modified checklist for autism in toddlers

\begin{tabular}{|l|l|}
\hline QUESTÃo & SIM \\
\hline 1. Seu filho gosta de balançar, de pular no seu joelho, etc.? & \\
\hline 2. Seu filho tem interesse por outras crianças? & \\
\hline 3. Seu filho gosta de subir em coisas, como escadas ou móveis? & \\
\hline 4. Seu filho gosta de brincar de esconder e mostrar o rosto ou de esconde-esconde? & \\
\hline $\begin{array}{l}\text { 5. Seu filho já brincou de faz de conta, como, por exemplo, fazer de conta que está falando } \\
\text { no telefone ou que está cuidando da boneca, ou qualquer outra brincadeira de faz-de-conta? }\end{array}$ & \\
\hline 6. Seu filho já usou o dedo indicador dele para apontar, para pedir alguma coisa? & \\
\hline 7. Seu filho já usou o dedo indicador dele para apontar, para indicar interesse em algo? & \\
\hline $\begin{array}{l}\text { 8. Seu filho consegue brincar de forma correta com brinquedos pequenos (ex.: carros ou } \\
\text { blocos), sem apenas colocar na boca, mexer no brinquedo ou deixar o brinquedo cair? }\end{array}$ & \\
\hline 9. O seu filho alguma vez trouxe objetos para você (pais) para lhe mostrar esse objeto? & \\
\hline 10. O seu filho olha para você no seu olho por mais de um segundo ou dois? & \\
\hline 11. O seu filho já apareceu muito sensível ao barulho? (ex.: tapando os ouvidos) & \\
\hline 12. O seu filho sorri em resposta ao seu rosto ou ao seu sorriso? & \\
\hline 13. O seu filho imita você? (ex.: quando você faz expressões e caretas) & \\
\hline 14. O seu filho responde quando você chama pelo nome? & \\
\hline 15. Se você aponta um brinquedo do outro lado do cômodo, o seu filho olha para eles? & \\
\hline 16. Seu filho já sabe andar? & \\
\hline 17. O seu filho olha para coisas que você está olhando? & \\
\hline 18. O seu filho faz movimentos estranhos com os dedos perto do rosto dele? & \\
\hline 19. O seu filho tenta atrair sua atenção para a atividade dele? & \\
\hline 20. Você alguma vez já se perguntou se seu filho é surdo? & \\
\hline 21. O seu filho entende o que as pessoas dizem? & \\
\hline $\begin{array}{l}\text { 22. O seu filho às vezes fica aéreo, "olhando para o nada" ou caminhando sem direção } \\
\text { definida? }\end{array}$ & \\
\hline 23. O seu filho olha para o seu rosto para conferir a sua reação quando vê algo estranho? & \\
\hline
\end{tabular}

Fonte: Muratori (2014)

Os testes Denver II $^{1}$ e BayleyIII ${ }^{3}$ foram tomados em seus resultados relativos à faixa etária de 24 meses. Os itens esperados para essa faixa etária estão resumidos no Quadro 4.

A escala Bayley III é um instrumento indicado para a avaliação de crianças de um a 42 meses de idade, com ou sem deficiência. A avaliação do desenvolvimento é realizada em cinco domínios: cognitivo, motor, linguístico, socioemocional e comportamento adaptativo. É considerada de fácil aplicação (30 a 90 minutos) e envolve atividades com brinquedos que facilitam a interação do bebê/ criança com o examinador ${ }^{3}$. Para a presente pesquisa foi utilizado o subitem linguagem, cuja aplicação foi realizada por terapeuta com formação específica no protocolo. Como a mesma filmou a aplicação, analisaremos os princípios de intersubjetividade e relação forma sentido durante a aplicação do subitem linguagem.

A aplicação do teste Bayley III foi realizada individualmente com a criança e seu responsável. Inicialmente foi explicado o objetivo do teste e solicitado que o responsável não interferisse nas atividades (a menos que fosse solicitado), pois a questão poderia não ser pontuada.

No teste Bayley III, o item de linguagem é subdividido em comunicação receptiva e comunicação expressiva. A comunicação receptiva abrange itens do comportamento pré-verbal, o desenvolvimento do vocabulário, a capacidade da criança na identificação de objetos e imagens, entre outros. Já a comunicação expressiva contempla itens da comunicação pré-verbal, como balbuciar, gesticular, o desenvolvimento do vocabulário, nomeando objetos e imagens, etc ${ }^{3}$.

Já o teste de Denver II foi elaborado para que profissionais da área de saúde fizessem a triagem de desenvolvimento em crianças de 0 a 6 anos $^{2}$. Ele é composto por 125 itens, que se dividem em quatro áreas: pessoal-social, motor fino adaptativo, linguagem e motor-grosseiro. Para alguns itens pede-se que a criança realize determinadas tarefas, para outros se considera o relato dos responsáveis. Cada um dos itens avaliados é classificado em: nor- 
Quadro 4. Itens esperados para 24 meses na avaliação dos testes Denver II e Bayley III

\begin{tabular}{|c|c|}
\hline DENVER II-Linguagem 24meses & BAYLEY III- Linguagem 24 meses \\
\hline $\begin{array}{c}\text { 18- aponta } 2 \text { figuras } \\
\text { 19- combina palavras } \\
20 \text { - cita } 1 \text { figura } \\
\text { 21- cita ou compreende partes do corpo } \\
22 \text { - aponta } 4 \text { figuras } \\
\text { 23- fala meio compreensível }\end{array}$ & $\begin{array}{c}\text { COMUNICAÇÃO RECEPTIVA } \\
\text { 15- identifica } 1 \text { objeto } \\
\text { 16- identifica } 1 \text { objeto no ambiente } \\
\text { 17- identifica } 1 \text { figura } \\
\text { 18- compreende palavras de repreensão } \\
19 \text { - identifica } 3 \text { objetos } \\
\text { 20- segue ordens de uma parte (ex. alimenta o bebê) } \\
21 \text {-identifica } 3 \text { figuras } \\
\text { COMUNICAÇÃO EXPRESSIVA } \\
\text { 20- nomeia } 1 \text { objeto } \\
\text { 21- combina palavra e gesto } \\
\text { 22- nomeia } 1 \text { figura }\end{array}$ \\
\hline
\end{tabular}

mal, cautela ou atraso. Considera-se normal quando a criança executa atividade prevista para a idade; cautela, quando a criança não executa ou recusa-se a realizar atividade que já é feita por 75 a $90 \%$ das crianças daquela idade, e atraso, quando a criança não executa ou recusa-se a realizar atividade que já é executada por mais de $90 \%$ dos que têm sua idade $^{1,2}$. Ele foi aplicado pelos pesquisadores antes ou após as filmagens realizadas entre mães e bebês.

Os Potenciais Evocados Auditivos Corticais (PEAC) são avaliações objetivas da atividade neuro elétrica na via auditiva (do nervo auditivo até córtex cerebral) em resposta a um estímulo acústico ${ }^{15}$, refletindo as características acústicas e temporais do estímulo. Por meio desta avaliação eletrofisiológica é possível obter informações da chegada do estímulo auditivo ao córtex e início do processamento cortical. A partir desta estimulação é possível saber se o sinal sonoro foi recebido adequadamente no córtex auditivo, tornando-se, nesse sentido, um instrumento de avaliação da sensibilidade auditiva funcional de modo mais completo. Nesta avaliação são analisadas as ondas geradas pelos estímulos freqüentes, pois são componentes que abrangem áreas do córtex auditivo primário (lobo temporal superior), secundário e sistema límbico com a interferência do processo maturacional e que independem da resposta do paciente ${ }^{16}$.

Também foram analisados vídeos de interação das mães com seus bebês e destes com o examinador por 15 minutos a partir mecanismos e estratégias enunciativas ${ }^{8}$. Os mecanismos e estratégias enunciativas estão descritos no Quadro 5 de modo a oferecer uma compreensão das operações lógicas envolvidas na análise. 
Quadro 5. Mecanismos e estratégias enunciativas

\begin{tabular}{|c|c|}
\hline $\begin{array}{l}\text { 10mecanismo enunciativo: } \\
\text { as relações de conjunção eu- } \\
\text { tu e de disjunção eu/tu. }\end{array}$ & 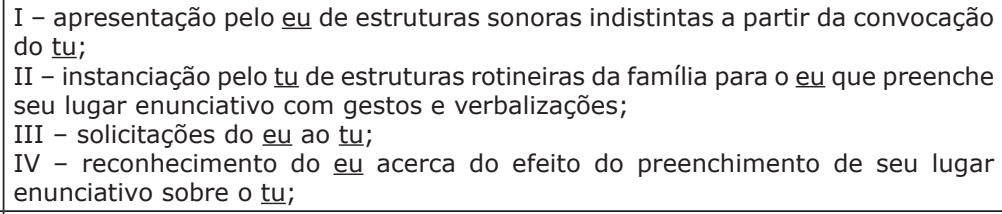 \\
\hline $\begin{array}{l}2^{\circ} \text { mecanismo enunciativo: } \\
\text { a semantização da língua e } \\
\text { a construção da referência } \\
\text { pela díade (eu-tu)/ele. }\end{array}$ & 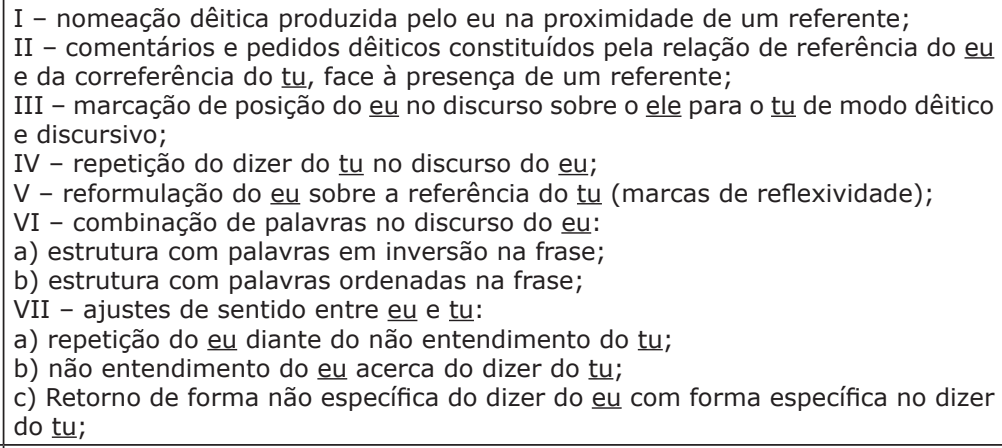 \\
\hline $\begin{array}{l}30 \text { mecanismo enunciativo: } \\
\text { a instauração do sujeito na } \\
\text { língua-discurso. }\end{array}$ & $\begin{array}{l}\text { I - do aparelho de funções: } \\
\text { a) através da intimação; } \\
\text { b) através da interrogação; } \\
\text { II - do aparelho de formas de instanciação do eu: } \\
\text { a) uso do nós; } \\
\text { b) oscilação entre terceira e primeira pessoa; } \\
\text { c) marca do eu no verbo; } \\
\text { d) instanciação do nome; } \\
\text { e) atualização de referência ao locutor com a forma pronominal eu; } \\
\text { III - Mecanismos de instanciação da dupla enunciação pelo eu: } \\
\text { a) recuperação da alocução anterior pelo eu através de indução do tu; } \\
\text { b) constituição do relato de ações e a posição do eu com o estabelecimento de } \\
\text { relação entre os tempos lingüísticos presente e passado; } \\
\text { c) constituição do relato de dizer e a posição do eu: } \\
\text { c.1)por projeção do eu de nova enunciação; } \\
\text { c.2) por retomada do eu de enunciação anterior; } \\
\text { d)simulação de eu de outra enunciação a criança brincando com o outro via língua. }\end{array}$ \\
\hline
\end{tabular}

Fonte: Silva (2009).

A análise dos resultados foi descritiva e por comparação dos distintos instrumentos e protocolos, a saber: a) pontuação obtida nos testes de linguagem DENVER II e BAYLEY III, b) resultados obtidos no roteiro IRDI, nos Sinais PREAUT e no MCHAT aos 24 meses quanto à presença ou não de risco psíquico; c) Análise dos mecanismos e estratégias enunciativas.

A seguir apresenta-se uma síntese das etapas da pesquisa:

- Até um mês dos bebês- captação dos bebês no teste do pezinho, assinatura TCLE, realização de entrevista inicial e do PEAC;

- Entre 3 meses e 1 mês e 4 meses e 29 dias- realização primeira fase IRDI, Sinais PREAUT, DENVER II, filmagem dos bebês sentados em bebê conforto de frente para suas mães; estas eram convidadas a cantar ( 3 minutos), con- versar com o bebê (3 minutos) e interagir com um brinquedo dado a mãe, que lhe oferece (3 minutos); 6 minutos com o bebê deitado sobre o tatame e interagindo com a mãe.

- Entre 5 meses e 1 dia e 6 meses e 29 dias- segunda fase do IRDI, DENVER II e filmagem idêntica à primeira fase. Realização do PEAC

- Entre 8 meses e 1 dia e 9 meses e 29 dias- terceira fase do IRDI, Sinais PREAUT, DENVER II e filmagem em que o bebê ficou sentado em tatame com a mãe e uma caixa com brinquedos da faixa etária. Essa filmagem foi livre, de 15 minutos.

- Entre 11 meses e 1 dia e 12 meses e 29 dias - DENVER II e filmagem igual à faixa etária anterior. Realização do PEAC.

- Entre 17 meses e 1 dia e 18 meses e 29 diasquarta fase do IRDI, DENVER II, filmagem 
igual à faixa etária anterior, com a entrada do pesquisador nos últimos 5 minutos. Realização do PEAC. Avaliação do Bayley III.

- Entre 23 meses e 1 dia e 24 meses e 29 diasDENVER II, filmagem igual à faixa etária anterior, com a entrada do pesquisador nos últimos 5 minutos. Aplicação do MCHAT na mãe antes da filmagem e checagem das respostas na filmagem e interação do pesquisador. Realização do PEAC. Avaliação do Bayley III.

A entrevista, as filmagens e aplicação do IRDI, Sinais PREAUT, Denver II e MCHAT foram realizadas na unidade de saúde. A avaliação do PEAC foi realizada no Hospital Universitário próximo à unidade. Já a avaliação do Bayley III foi realizada por colega especializada nesta avaliação no serviço de atendimento fonoaudiológico ou na residência de uma das crianças que não pôde comparecer ao serviço.

As filmagens foram visualizadas por fonoaudiólogas da pesquisa para identificação dos mecanismos e estratégias enunciativos. O roteiro IRDI e Sinais PREAUT foram aplicados durante a observação dos bebês na unidade e também conferidos nas filmagens pela orientadora e psicólogas da equipe.

\section{Resultados}

Nesta seção, inicia-se com o resumo dos resultados das avaliações, para, a seguir, explorar cada caso individualmente. Eles estão dispostos nas Tabelas 1 e 2 .

Tabela 1. Resultados avaliações de linguagem e risco psíquico

\begin{tabular}{|c|c|c|c|}
\hline Sujeito & A. & R. & $\mathbf{P}$ \\
\hline $\begin{array}{l}\text { Bayley III } \\
24 \text { meses }\end{array}$ & $\begin{array}{c}47 \\
\text { Extremamente baixo }\end{array}$ & $\begin{array}{c}47 \\
\text { Extremamente baixo }\end{array}$ & $\begin{array}{c}79 \\
\text { Limítrofe }\end{array}$ \\
\hline $\begin{array}{l}\text { Denver II - } \\
24 \text { meses }\end{array}$ & $\begin{array}{c}83 \\
\text { Suspeito }\end{array}$ & $\begin{array}{c}0 \\
\text { Alterado }\end{array}$ & $\begin{array}{l}100 \\
\text { Normal }\end{array}$ \\
\hline $\begin{array}{c}\text { IRDI } \\
\text { Indicadores ausentes }\end{array}$ & $\begin{array}{c}1,3,4,6,7,8,11,13,16 \\
17,18,20,21\end{array}$ & $\begin{array}{c}1,4,5,8,9,11,12,13,15 \\
17,20,21,22\end{array}$ & Nenhum \\
\hline Classificação & Com risco & Com risco & Sem risco \\
\hline & $4 m=9$ e $9 m=9$ & $4 m=3$ e $9 m=7$ & $4 m$ e $9 m=15$ \\
\hline $\begin{array}{c}\text { PREAUT escore Sinais } \\
\text { Ausentes }\end{array}$ & $\begin{array}{l}4 m=2 a, 2 b, 3 a, 3 b, 3 c, 4 c \\
9 m=2 a, 2 b, 3 a, 3 b, 3 c, 4 c\end{array}$ & $\begin{array}{c}4 \mathrm{~m}=1 \mathrm{a}, 1 \mathrm{~b}, 2 \mathrm{a}, 2 \mathrm{~b}, 2 \mathrm{c} \\
3 \mathrm{a}, 3 \mathrm{~b}, 3 \mathrm{c}, 4 \mathrm{c} \\
9 \mathrm{~m}=2^{\mathrm{a}}\end{array}$ & Nenhum \\
\hline Direção do risco & Risco não autístico & Risco para autismo aos $4 \mathrm{~m}$ & Sem risco \\
\hline MCHAT 24 meses & Sem risco & Com risco para autismo & Sem risco \\
\hline $\begin{array}{c}\text { Mecanismos e } \\
\text { estratégias enunciativas }\end{array}$ & $\begin{array}{c}2^{\circ}-\text { II, III,IV e VIb } \\
3^{\circ} \mathrm{Ib}\end{array}$ & $10-\mathrm{I}, \mathrm{II}$ & $2^{\circ}-\mathrm{I}, \mathrm{II}, \mathrm{IV}$ \\
\hline
\end{tabular}


Tabela 2. Análise mecanismos e estratégias enunciativas

\begin{tabular}{|c|c|c|c|}
\hline & $\begin{array}{l}\text { 10 Mecanismo: as relações de } \\
\text { conjunção eu-tu e de disjunção } \\
\text { eu/tu. }\end{array}$ & $\begin{array}{l}20 \text { Mecanismo: a semantização } \\
\text { da língua e a construção da } \\
\text { referência pela díade (eu-tu)/ele. }\end{array}$ & $\begin{array}{l}3^{\circ} \text { Mecanismo:a instauração do } \\
\text { sujeito na língua-discurso. }\end{array}$ \\
\hline A & Possui por implicação lógica & $\begin{array}{l}\text { Estratégias } \\
\text { II) Responde para a mãe com } \\
\text { pronome dêitico "aqui", quando } \\
\text { questionado onde está o } \\
\text { brinquedo. Criança diz "Oh mãe" } \\
\text { mostrando brinquedo. } \\
\text { IV-A mãe solicita à criança para } \\
\text { que diga "boi, auau, pintinho" e } \\
\text { ela repete. } \\
\text { VI-b- Criança produz "dá mama". } \\
\text { Solicitando mamar no seio. }\end{array}$ & $\begin{array}{l}\text { Estratégia: } \\
\text { Ib=Criança se dirige a mãe e } \\
\text { pergunta: "papai?" }\end{array}$ \\
\hline$R$ & $\begin{array}{l}\text { Estratégias: } \\
\text { I) Criança vocaliza algo } \\
\text { ininteligível em uma brincadeira } \\
\text { que a mãe faz e ela parece gostar. } \\
\text { II) Imita a mãe com gesto. }\end{array}$ & Ausente & Ausente \\
\hline$P$ & Possui por implicação lógica & $\begin{array}{l}\text { Estratégias: } \\
\text { I)Criança produz "ati" para } \\
\text { carrinho. } \\
\text { II)Criança pede a bola para a } \\
\text { mãe, "a bo, a bo". } \\
\text { IV) A mãe fala: o gato, e a criança } \\
\text { repete: "o gato". }\end{array}$ & Ausente \\
\hline
\end{tabular}

Caso A. - Um bebê do sexo masculino nascido a termo (39 semanas de idade gestacional, 3400 gramas ao nascer, com apgar 10 no primeiro e quinto minutos). Ele possuía uma irmã mais velha de oito anos. A. foi planejado e desejado pelos pais que viviam com os filhos em uma propriedade rural. Recebeu aleitamento materno exclusivo até o sexto mês, embora, por vezes, se engasgasse. A mãe de A. não fez referência a qualquer sofrimento psíquico durante a gravidez ou no pós-parto. Observou-se durante a investigação que, embora utilizasse o manhês demonstrando prazer em estar com seu bebê, apresentava na primeira etapa da pesquisa dificuldades em supor o que seu bebê desejava, ou seja, dificuldades no estabelecimento da demanda considerando os eixos teóricos do IRDI.

Quanto aos dados sociodemográficos, a mãe possuía ensino médio completo, não atuava profissionalmente, cuidando apenas do lar, e a renda per capita da família era de trezentos e cinquenta e sete reais.

Caso R. - Bebê do sexo masculino, nascido a termo (39 semanas, 2905 gramas, apgar 9 no primeiro e 10 no quinto minuto), com gestação não planejada. Durante a gravidez a mãe descobriu que o pai de R. tinha um relacionamento paralelo e que havia engravidado outra mulher. Apesar disso, o casal tentou viver junto, mas se separou quando o menino estava com nove meses.

O período gestacional foi muito difícil. Ela apresentou deslocamento de placenta e dores muito fortes. Esse sofrimento persistiu no período pós-gestacional em função das dificuldades com o cônjuge.

Desde o início, R. apresentou dificuldades no contato com os outros, e momentos de intenso sofrimento sobretudo diante de estímulos sensoriais fortes. Sofreu de refluxo-gastro-esofágico e foi medicado para tanto até 24 meses. Alimentava-se bem até esta idade, mas após cessar o remédio para refluxo-gastro-esofágico desenvolveu seletividade alimentar importante.

Em função dos sinais de risco psíquico, $\mathrm{R}$. recebeu intervenção precoce dos 10 aos 12 meses com terapeuta ocupacional. Desde os 18 meses está sendo chamado a retornar à terapia, mas a mãe não tem como levá-lo. Aos 38 meses, está retomando o atendimento domiciliar com fonoaudióloga, e espera-se que em 2018 possa retomar trabalho com outra profissional da terapia ocupacional em função da seletividade alimentar e do atraso de linguagem que persiste. 
Caso P. - Bebê do sexo masculino, nascido pré-termo (32 semanas 3 dias, $1.445 \mathrm{~g}$, apgar 4 no primeiro e 7 no quinto minuto), com gestação não planejada. A mãe engravidou aos 35 anos, possuindo outros filhos de 18, 16 e 10 anos. Durante a gestação e o nascimento os pais estavam casados, sendo que no segundo ano de P. se separaram. Mãe não relatou intercorrências durante a gestação, bem como não refere sofrimento psíquico no pré e pós-parto.

P. não apresentou risco psíquico, nem ao desenvolvimento, nas avaliações realizadas (PREAUT, MCHAT e IRDI), conforme Quadro 3.

No Quadro 3, estão expostos os resultados obtidos na análise das avaliações dos três casos.

É possível perceber que A. e R. apresentam um escore de risco no Bayley III, o que não se reflete no teste de triagem Denver II - aspecto linguagem não diferencia bem os três sujeitos. Observe-se que no teste Bayley III aparece o maior comprometimento de R. e P. ambos com risco psíquico.

$\mathrm{Na}$ análise dos mecanismos enunciativos, que buscam observar a interação linguística, as diferenças são mais claras, pois apenas A. possui o terceiro mecanismo demonstrando maior potencialidade linguística do que R. que possui só o primeiro, e do que P. que possui o segundo e, por implicação lógica, o primeiro. Assim, de um ponto de vista enunciativo, A. tem mais potencialidades do que os dois outros sujeitos conforme se pode observar nos exemplos de fala no quadro 4.

No caso de A. fica evidente, em termos psíquicos, aos quatro meses, a dificuldade de a mãe estabelecer a demanda e supor um sujeito (indicador 1- quando a criança chora a mãe sabe o que ela quer) e alternar presença e ausência (indicador 4- a mãe propõe algo e aguarda o que a criança quer). $\mathrm{Na}$ análise dos Sinais PREAUT observou-se que A. não apresentava o terceiro tempo do circuito pulsional, embora pudesse buscar espontaneamente tanto o examinador quanto a mãe (sinal $1 \mathrm{~A})$. $\mathrm{Na}$ fase II do IRDI ele evidenciou dificuldades em diferenciar o dia da noite (indicador 6), de utilizar distintos sinais para se expressar (indicador 7) e em solicitar algo a sua mãe e aguardar a resposta da mesma (indicador 8). Ele também não procurava ativamente o olhar materno (indicador 11) e não solicitava auxílio (indicador 13). Havia, portanto, dificuldades no exercício de ambas as funções parentais, o que persiste na fase III, em que A. não estranhava pessoas desconhecidas (indicador 18), não demonstrava gostar ou não de alguma coisa (indicador 16), não estabelecia uma linguagem particular com a mãe (indicador 17), e não fazia gracinhas (indicador 20). Portanto, não havia uma dinâmica alienação separação bem estabelecida. Apesar dessas dificuldades no IRDI e nos Sinais PREAUT, aos 24 meses A. não possuía risco pela análise do M-CHAT já que não se tratava de uma dificuldade de tipo autista, mas uma dificuldade no laço em função de falhas no exercício das funções parentais.

$\mathrm{Na}$ linguagem fica evidente o atraso de A. no teste Bayley III pela pontuação extremamente baixa e o resultado suspeito no teste DENVER II. Já na análise enunciativa, é possível observar a pontencialidade de A. No entanto, quando se olham os exemplos no Quadro 4, percebe-se que embora ele apresente estratégias dos três mecanismos enunciativos ele parece ter um funcionamento de linguagem atrelado a solicitações de repetição de palavras por parte da mãe ou ao pedido de mamá. Não se percebe na filmagem que haja uma boa sustentação do diálogo com A. por parte da mãe.

$\mathrm{O}$ bebê R., apesar de ter pontuado em duas tarefas no Bayley III, zerou o item da comunicação receptiva, pois não realizou três tarefas consecutivas, como indica a norma do teste. É possível identificar itens importantes do desenvolvimento da linguagem que R. não foi capaz de realizar, tais como: bebê não olha a pessoa momentaneamente, não se acalma quando falam com ele, não procura virando a cabeça, não responde nem interrompe a atividade quando chamam por ele. Na comunicação expressiva ele faz pelo menos uma combinação de consoante com vogal, participa de rotinas com brincadeiras e tagarela expressivamente. Porém, não faz uso de aproximação de uma palavra (ex. olhar a mamadeira e pedir pelo "mamá"), não imita palavras e não inicia interação com brincadeiras.

Neste caso, ficam evidentes as limitações gramaticais, tanto na avaliação do Bayley III e DENVER II, quanto às limitações intersubjetivas no processo de semantização da língua verificadas na análise enunciativa, pois R. não busca o interlocutor e não desenvolveu conhecimento mínimo da língua. Esse atraso demonstra os efeitos nefastos do autismo tanto na construção do conhecimento gramatical quanto na sustentação de uma posição enunciativa por sua mãe e por ele, pois não há emergência de sinais de diálogo entre ambos. A mãe lhe dirige uma fala pouco sintonizada ao que 
R. parece estar sentindo e ele é incapaz de convocá-la e de processar o que a mãe lhe diz. Isso fica visível quando se observam os resultados dos Sinais PREAUT e do IRDI.

O bebê R. quando analisados os resultados das avaliações psíquicas, demonstra sinais claros de uma estrutura de tipo autista porque não procurava espontaneamente o adulto, fosse o examinador ou a mãe, e não procurava suscitar trocas prazeirosas com eles (conforme se vê nos sinais PREAUT ausentes) e em alguns indicadores como o 5 (não havia troca de olhares com a mãe) e não reagia ao manhês ( indicador 3). A mãe de R. tinha dificuldade de propor algo e aguardar a resposta do filho (indicador 4) e de saber o que ele queria quando chorava, já que muito de seu choro tinha a ver com possíveis consequências do sofrimento sensorial (hipersensibilidade corporal) e pela presença do refluxo-gastro-esofágico).

Na segunda fase de avaliação do IRDI demonstrou não aguardar a resposta materna para suas solicitações (indicador 8), não buscava ativamente o olhar materno (indicador 11) e mantinha-se passivo sem pedir ajuda (indicador 13). A mãe, por sua vez, não lhe dirigia pequenas frases (indicador 9) e havia dificuldade da mãe em dar suporte ao bebê sem poupar-lhe esforço (indicador 12). Na fase III as dificuldades se mantiveram pela ausência de busca de troca prazeirosa com a mãe (indicador 15), não partilhavam linguagem particular (indicador 17), R. não fazia gracinhas (indicador 20), ele também não buscava olhar de aprovação do adulto que é uma conduta intersubjetiva (indicador 21) e não aceitava alimentação semi-sólida, sólida e variada. Essas dificuldades se confirmaram pelo risco para autismo ainda presente no M-CHAT aos 24 meses.

É importante ressaltar que o bebê R. realizou intervenção precoce com foco no processo de alienação inicial, com estratégias psicomotoras e lúdicas para fisgá-lo na relação. Esta terapia foi realizada por terapeuta ocupacional com formação em psicanálise e ocorreu durante dois meses, quando ele estava na faixa etária de 10 a 12 meses. No histórico desse bebê, ele apresentou, em alguns momentos, a emergência dos Sinais PREAUT aos 12 meses, mas seguiu sendo referido para intervenção em função da não superação do risco após interrupção dessa intervenção entre 10 e 12 meses.

$\mathrm{O}$ bebê P., sem risco psíquico, demonstrou no Denver II resultados na média e, no Bayley III, limítrofe. Neste caso, o roteiro enunciativo evidenciou a ausência do terceiro mecanismo enunciativo que se relaciona à possibilidade de se inscrever discursivamente na linguagem a partir das funções do aparelho enunciativo como interrogação e intimação, as marcações do sujeito no discurso a partir do próprio nome ou uso do pronome EU e a possibilidade de os resultados na média e limítrofe respectivamente. Além disso, diferiram também nos mecanismos enunciativos já que na filmagem P06 apresentou ausência do terceiro mecanismo. Por meio do Potencial Evocado Auditivo Cortical, observou-se que P. apresentou maior latência do componente P1 (136ms) no Potenical Evocado Auditivo Cortical (PEAC) quando comparado a crianças nascidas a termo e que, ao nascimento, não possuía este componente do PEAC.

No Bayley III, P. não compreendia palavras de repreensão, não seguia ordens simples, não identificava três itens do vestuário, partes do corpo e figuras de ação. Na comunicação expressiva ele não respondia perguntas com sim ou não, não fazia frases simples, não nomeava mais de um objeto e uma figura. Demonstrava, portanto, um atraso de linguagem que se manifestou também na emergência de estratégias no segundo mecanismo enunciativo, pois não combinava palavras para formação de frases. Os exemplos de linguagem espontânea evidenciam que ele estava começando a falar suas primeiras palavras. As tarefas pontuadas indicaram que P. identificava objetos e figuras de livro, localizava objetos no ambiente, dirigia atenção aos outros, imitava pelo menos uma palavra, iniciava interação com brincadeiras, usava oito palavras apropriadamente, utilizava palavras para demonstrar desejos, combinava palavra e gesto. Portanto, as limitações parecem estar mais presentes no domínio gramatical do que no aspecto intersubjetivo da linguagem, visto que não possuía risco psíquico.

\section{Discussão}

Com o presente trabalho foi possível verificar que a escala Bayley III e a análise enunciativa complementam-se em seus resultados, e que apesar da Bayley III ser uma avaliação padronizada que foca mais nas habilidades infantis, ela também abrange questões que abordam as reações da criança ao alocutário, o que permite analisar, ao menos parcialmente, cenas de diálogo, como, por exemplo, nos itens que avaliam se a criança olha a 
pessoa momentaneamente, presta atenção quando alguém fala ou move-se, acalma-se quando falam com ela (itens 1,2,3 da linguagem receptiva) ${ }^{3}$. Esses itens, de certa forma, avaliam a intersubjetividade, sobretudo a orientação às pessoas, o que permite hipotetizar que poderiam estar menos desenvolvidos em crianças com risco psíquico. Isso pôde ser observado nos casos com risco psíquico, sobretudo em relação à R., que demonstrou características de autismo.

Há estudos ${ }^{17,18}$, em que a Bayley III é classificada como a melhor escala para avaliação do desenvolvimento infantil a partir dos 18 meses, e está entre os melhores instrumentos, pois seus dados são válidos, confiáveis e objetivos para a comunidade acadêmica, inclusive quando comparada ao DENVER II, o que se observou nesta pesquisa, na qual o Denver mostrou-se pouco fidedigno em três dos quatro casos apresentados. Esse resultado concorda com outro estudo ${ }^{7}$, que também indica que o Teste Denver II apresenta capacidade limitada além de ser considerado um teste de valor questionável em termos de triagem para atraso de desenvolvimento $^{19}$. Outras limitações encontradas neste teste estão relacionadas ao baixo valor diagnóstico, pois parece insuficiente para avaliar mudanças qualitativas ao longo do tempo e detectar precocemente alterações sutis do desenvolvimento ${ }^{20}$.

Os roteiros de avaliação do risco psíquico IRDI e PREAUT foram compatíveis em seus resultados. Apesar de os sinais PREAUT serem elaborados inicialmente para a detecção do risco para autismo, assim como o IRDI, apresenta sensibilidade para verificar a presença de outros problemas do desenvolvimento como risco à psicose e risco à aquisição da linguagem ${ }^{12}$. O risco para autismo de R., identificado pelos Sinais PREAUT foi confirmado na avaliação do M-CHAT.

Nesse sentido, A. provavelmente não seria tratado quanto ao risco psíquico se não tivessem sido observados o roteiro IRDI e os Sinais PREAUT, uma vez que o M-CHAT não indicou risco neste caso. Dessa forma, a abordagem utilizada seria apenas fonoaudiológica para o seu atraso de linguagem. Isso evidencia a importância da avaliação do risco psíquico aliada às avaliações de linguagem ${ }^{10}$, bem como a escolha correta dos protocolos, uma vez que a concepção do M-CHAT tem por base o olhar dos sintomas e não da estruturação do psiquismo como permitem o roteiro IRDI e os Sinais PREAUT.
No caso de A. o risco psíquico é de natureza não autista. Nesse caso, o risco é mais evidente em relação ao laço materno, pois obteve diversos indicadores ausentes na avaliação com IRDI, e obteve pontuação 9 no questionário PREAUT. Essa pontuação intermediária demonstra que pode haver risco psíquico que se apresenta no estabelecimento do laço, mas por dificuldades no cuidado parental ${ }^{20}$. Portanto, percebe-se uma dificuldade na sintonia da mãe com a atividade do bebê e certo desencontro entre os dois, que não permitiu o estabelecimento do terceiro tempo do circuito pulsional. Neste caso, porém, o não estabelecimento do terceiro tempo não significa risco de autismo visto que A., diferentemente de R., tem orientação a pessoas e as busca, demonstrando maior dificuldade na relação com a mãe.

As dificuldades no laço no caso de A. evidenciam-se em limitações no diálogo de tipo colagem às solicitações da mãe, nos exemplos das estratégias dos mecanismos enunciativos, mesmo que ele possua os três mecanismos estabelecidos. Fica clara, neste caso, a necessidade de propor uma hipótese do funcionamento da linguagem a partir do olhar intersubjetivo, ou seja, da observação do funcionamento de linguagem com a mãe ${ }^{8-10}$. Verificou-se que o teste Bayley III classificou a linguagem como extremamente baixa, o que demonstrou mais claramente as dificuldades nas habilidades linguísticas. Já na análise enunciativa é possível verificar que A. possui grande potencialidade para desenvolver o conhecimento linguístico se puder apresentar um funcionamento de linguagem em que seja sustentada sua autonomia discursiva.

Estudos indicam que há relação do risco psíquico com atraso de linguagem ${ }^{10,11}$, o que fica evidente nos casos de A. e R. No caso de P. a prematuridade parece ser um fator de risco mais importante para a emergência do atraso de linguagem, tanto pelas limitações na maturação auditiva, evidente neste bebê, quanto pelas limitações linguísticas demonstradas por ele. No caso de P., há constatação de atraso na aquisição da linguagem por meio de uma classificação limítrofe na avaliação padronizada pelo Bayley III e ainda a ausência do terceiro mecanismo enunciativo. Esse fato é explicado pelo nascimento prematuro, pois estudos comprovam que crianças prematuras podem apresentar atrasos no desenvolvimento ${ }^{21,22}$.

Ainda sobre os resultados obtidos no teste Bayley III no caso P., a análise demonstrou menor 
desempenho na linguagem receptiva do que na linguagem expressiva, o que corrobora com outros estudos com bebês prematuros ${ }^{23-26}$, que também indicaram maior déficit na compreensão de linguagem. Esses resultados podem estar relacionados ao atraso na maturação da via auditiva verificado por meio do PEAC. Há uma diferença significativa entre as latências e as amplitudes das ondas geradas em respostas corticais, estando aumentadas em prematuros ${ }^{27}$.

Quanto a R., há risco psíquico detectado pelas três avaliações: no IRDI e nos Sinais PREAUT, pois abrangem questões que dizem respeito à ausência de evidências do terceiro tempo do circuito pulsional, ou seja, dificuldades na alienação, e o M-CHAT que, de um lugar desenvolvimentista é específico para autismo em idades mais avançadas. É evidente, também, o atraso de linguagem demonstrado em todas as avaliações. No caso de R. há um desenvolvimento de linguagem comum a sujeitos com autismo, como a dificuldade de apreender concei$\operatorname{tos}^{28}$. Também evidencia importante dificuldade no terceiro mecanismo enunciativo ${ }^{9}$ como a aquisição do pronome EU, ou seja, alterações que atingem tanto o domínio gramatical como o discursivo ${ }^{29}$.

É importante considerar o fato de que R. realizou aproximadamente dois meses de intervenção precoce com terapeuta ocupacional. Acredita-se que essa intervenção facilitou a emergência da capacidade de imitar, mas não foi suficiente para fazer evoluir a linguagem, o que põe em questão a ideia de terapeuta único nesses casos.

Estudos $^{30,31}$ afirmam que por meio da intervenção fonoaudiológica é possível trabalhar a interação social (contato visual e compartilhamento de atividades), além da linguagem. Alguns aspectos devem ser considerados na intervenção terapêutica em casos de autismo, dentre eles o fato de ser um trabalho que exige tempo para alcançar resultados. R. ficou pouco tempo em terapia, o que não permitiu sustentar as evoluções necessárias, tanto em termos de constituição psíquica quanto para o processo de aquisição da linguagem, embora tenha permitido algumas evoluções ${ }^{31}$.

De um modo geral, a análise dos casos sugere que o fonoaudiólogo deve estar atento ao risco psíquico nos casos com atraso de linguagem, pois alguns terão somente o atraso (P.), e outros poderão estar associados a uma psicopatologia que ainda está em fase de estruturação (A.) ou já estruturada
(R.). Esse fato pôde ser observado no desfecho dos três casos.

Os bebês com risco psíquico A. e R. foram encaminhados precocemente para intervenção em tempo, mas apenas quando emergiu o atraso de linguagem os familiares passaram a se preocupar e aderir ao tratamento. O acompanhamento longitudinal dos bebês com histórico de risco psíquico e ao desenvolvimento demonstra a importância da puericultura e facilitação de acesso à intervenção em tempo, talvez por meio de estratégias mais próximas à moradia dos bebês, visto que o acesso ao local de atendimento foi uma das justificativas para o não comparecimento à intervenção continuada, sobretudo no caso de R.

\section{Conclusão}

A comparação entre as formas de avaliação da linguagem permitiu identificar a diferença entre testes padronizados e um roteiro de avaliação enunciativa, pois a limitação em mecanismos enunciativos permitiu identificar as limitações de linguagem relacionadas com alterações na intersubjetividade. Isso ficou restrito quando se olha o Bayley III em que apenas um item contempla essa análise.

Verificou-se também que a escala Bayley III oferece melhor suporte, como avaliação padronizada do domínio gramatical, quando comparada com a escala de Denver II que deve ser mais restrita ao processo de triagem.

No que se refere aos resultados das avaliações dos casos descritos, constatou-se que a associação entre risco psíquico e atraso de linguagem foi mais significativa no autismo, do que no risco de tipo não autista. A prematuridade confirmou-se como um fator de risco biológico importante à aquisição da linguagem pelos efeitos tanto na maturação auditiva, quanto na construção da compreensão linguística. Os resultados indicam a importância de o fonoaudiólogo estar atento ao histórico de risco psíquico nos casos de atraso na aquisição da linguagem.

\section{Referências}

1. Frankenburg WK, Dodds J, Archer P, Shapiro H, Bresnick B. Denver II: training manual. Denver: Denver Developmental Materials; 1992. 
2. Brito CML. et al. Desenvolvimento neuropsicomotor: o teste de Denver na triagem dos atrasos cognitivos e neuromotores de pré escolares. Cad. Saúde Pública. 2011; 27(7): 1403-14.

3. Bayley Scales of Infant and Toddler Development - Third Edition, Administration Manual. San Antonio, TX: The Psychological Corporation, 2006.

4. Madaschi V. Tradução, Adaptação Transcultural E Evidências De Validade Das Escalas Bayley III De Desenvolvimento Infantil Em Uma População Do Município De Barueri, São Paulo. [Dissertação] São Paulo (SP), Universidade Presbiteriana Mackenzie; 2012.

5. Torras-Mañá M, Gómez-Morales A, González-Gimeno I.; Fornieles-De A.; \&Brun-Gasca C. Assessment of cognition and language in the early diagnosis of autism spectrum disorder: usefulness of the Bayley Scales of infant and toddler development, third edition. Journal of Intellectual Disability Research. 2016; 60 (5): 502-11.

6. Ballot, Daynia E. et al. Use of the Bayley Scales of Infant and Toddler Development, Third Edition, to Assess Developmental Outcome in Infants and Young Children in an Urban Setting in South Africa. International Scholarly. BMJ Paediatrics Open, 2017; 1 (1): 91.

7. Godamunne P, Liyanage C, Wimaladharmasooriya N, Pathmeswaran A, Wickremasinghe AR, Patterson C, et al. Comparison of performance of Sri Lankan and US children on cognitive and motor scales of the Bayley scales of infant development. BMC Res Notes. 2014; 7(1): 1.

8. Silva CLC. A criança na linguagem: enunciação e aquisição. Campinas: Pontes, 2009

9. Bender S, Surreaux LM. Os Efeitos Da Fala Da Criança: A Escuta Do Sintoma Na Clínica De Linguagem. Cadernos do IL. Porto Alegre, 2011; 42: 129-45.

10. Oliveira LD, Ramos-Souza AP. O Distúrbio De Linguagem Em Dois Sujeitos Com Risco Para O Desenvolvimento Em Uma Perspectiva Enunciativa Do Funcionamento De Linguagem Rev. CEFAC. 2014; 16(5): 1700-12.

11. Vendruscolo J, Ramos-Souza AP. Intersubjetividade no olhar interdisciplinar sobre o brincar e a linguagem de sujeitos com risco psíquico. São Paulo. CEFAC. 2015; 17(3): 707-19.

12. Kupfer MCM. (coord) Relatório Científico final: leitura da constituição e da psicopatologia do laço social por meio de indicadores clínicos: uma abordagem interdisciplinar atravessada pela psicanálise. Projeto temático FAPESp n.2003/09687-7, 2008.

13. Crespin G, Parlato-Oliveira E. Preaut (project). In: Jerusalinsk A. Autism Dossier (Dossiè Autism). 1ed. São Paulo: Instituto Langage, 2015.

14. Muratori F. O diagnóstico precoce no autismo: guia prático para pediatras. 1 ed. Salvador: Ed. Núcleo Interdisciplinar de Intervenção Precoce de Bahia, 2014.

15. Magliaro FCL, Scheuer CI, Assumpção Júnior FB, Matas CG. Estudo dos potenciais evocados auditivos em autismo. Pró-Fono Revista de Atualização Científica. 2010 jan-mar; 22(1): 31-6.

16. Reis ACMB, Frizzo ACF. Potencial evocado auditivo de longa latência. In: Bevilacqua MC et al. Tratado de audiologia. São Paulo: Santos; 2012
17. Moreira RS, Figueiredo EM. Instrumentos De Avaliação Para Os Dois Primeiros Anos De Vida Do Lactente. Journal of Human Growth and Development 2013; 23(2): 215-21.

18. Madaschi V, Paula CS. Medidas De Avaliação Do Desenvolvimento Infantil: Uma Revisão Da Literatura Nos Últimos Cinco Anos. Cadernos de Pós-Graduação em Distúrbios do Desenvolvimento 2011; 11(1): 52-56.

19. Moreira RS, Figueiredo M. Instrumentos de avaliação para os dois primeiros anos de vida do lactente. Journal of Human Growth and Development. 2013; 23(2): 215-21.

20. Roth AM. Sinais de risco psíquico em bebês na faixa etária de três a nove meses e sua relação com variáveis obstétricas sociodemográficas e psicosociais. [Dissertação]. Santa MariaRS: Universidade Federal de Santa Maria; 2016.

21. Fernandes LV, Goulart AL, Santos AMND, Barros MCDM, Guerra CC, \&Kopelman BI. Neurodevelopmental assessment of very low birth weight preterm infants at corrected age of 18-24 months by Bayley III scales. Jornal de pediatria. 2012; 88(6): 471-478

22. Serenius F, Källén K, Blennow M, Ewald U, Fellman V, Holmström G \&Olhager E. Neurodevelopmental outcome in extremely preterm infants at 2.5 years after active perinatal care in Sweden. Jama. 2013; 309(17): 1810-1820.

23. Góes FVD, Méio MDB, Mello RRD, \& Morsch D. Evaluation of neurodevelopment of preterm infants using Bayley III scale. Revista Brasileira de Saúde Materno Infantil. 2015; 15(1): 47-55.

24. Kiselev SY, L'vova OA, Gliga T, Bakushkina NI, Suleimanova EV, Grishina K I et al. The assessment of neurocognitive functions in premature infants in the first year of life using Bayley Scales. Zhurnalnevrologii i psikhiatriiimeni SS Korsakova. 2016; 116.4(2): 62-67.

25. Maggiolo M, Varela V, Arancibia C, \& Ruiz F. Dificultades de linguaje em niños preescolares con antecedente de prematuridad extrema. Revista chilena de pediatria. 2014; 85(3): 319-327.

26. Stene-Larsen K, Brandlistuen RE, Lang AM, Landolt MA, Latal B, \& Vollrath, ME. Communication impairments in early term and late preterm children: a prospective cohort study following children to age 36 months. The Journal of pediatrics, 2014; 165(6), 1123-1128

27. Pasman JW, Rotteveel JJ, de Graaf R, Stegeman DF, \& Visco YM. The effect of preterm birth on brainstem, middle latency and cortical auditory evoked responses (BMC AERs). Early human development, 1992; 31(2), 113-29.

28. Silva RA, Herrera SAL, Vitto LPM. Distúrbio De Linguagem Como Parte De Um Transtorno Global Do Desenvolvimento: Descrição De Um Processo Terapêutico Fonoaudiológico. Rev Soc Bras Fonoaudiol. 2007; 12(4): 322-8.

29. Delfrate CB, Santana APO, Massi GAA. Aquisição De Linguagem Na Criança Com Autismo: Um Estudo De Caso. Psicologia em Estudo, Maringá. 2009; 14(2): 321-31.

30. Tamanaha AC, Chiari BM \&Perissinoto J. A eficácia da intervenção terapêutica fonoaudiológica nos distúrbios do espectro do autismo. Revista CEFAC. 2015; 17(2): 552-558.

31. Klinger EF \& Souza APR. Análise clínica do brincar de crianças do espectro autista. Distúrbios da Comunicação. 2015; 27(1): 15-25. 